\title{
Erratum to: Health-related Internet use by lupus patients in southern Spain
}

\author{
José-Luis Callejas-Rubio • Raquel Ríos-Fernández • Ana-Celia Barnosi-Marín • \\ Francisco-José García-Hernández • José-Antonio Vargas-Hitos • \\ María-Teresa Camps-García • José-Antonio González-Nieto • \\ Julio Sánchez-Román • Juan Jiménez-Alonso • \\ Enrique de Ramón Garrido • Norberto Ortego-Centeno
}

Published online: 28 January 2014

(C) Clinical Rheumatology 2014

\section{Erratum to: Clin Rheumatol \\ DOI 10.1007/s10067-013-2395-Z}

The original version of this article unfortunately contains an error in the name of one of the authors. The name of author Norberto Otego-Centeno should be corrected to Norberto Ortego-Centeno.

The online version of the original article can be found at http://dx.doi.org/ 10.1007/s10067-013-2395-z.

J.-L. Callejas-Rubio $\cdot$ R. Ríos-Fernández $(\triangle) \cdot$ N. Ortego-Centeno Systemic Autoimmune Diseases Unit, Hospital San Cecilio, Avda Dr Olóriz 16, 18012 Granada, Spain

e-mail: rriosfer@hotmail.com

\section{A.-C. Barnosi-Marín}

Systemic Autoimmune Diseases Unit, Hospital Torrecárdenas,

Almería, Spain

F.-J. García-Hernández • J. Sánchez-Román

Collagenosis and Pulmonary Hypertension Unit, Hospital Virgen del

Rocío, Sevilla, Spain

J.-A. Vargas-Hitos $\cdot$ J. Jiménez-Alonso

Systemic Autoimmune Diseases Unit, Hospital Virgen de las Nieves,

Granada, Spain

M.-T. Camps-García • E. de Ramón Garrido

Systemic Autoimmune Diseases Unit, Hospital Carlos Haya,

Málaga, Spain

J.-A. González-Nieto

Systemic Autoimmune Diseases Unit, Hospital Juan Ramón

Jiménez, Huelva, Spain 